\title{
Water-soluble polyphenol-rich clove extract lowers pre- and post-prandial blood glucose levels in healthy and prediabetic volunteers: an open label pilot study
}

Ratheesh Mohan', Svenia Jose ${ }^{1}$, Johannah Mulakkal², Darla Karpinsky-Semper ${ }^{3} \mathbb{D}$, Andrew G. Swick ${ }^{3}$ and I. M. Krishnakumar ${ }^{2^{*}}$

\begin{abstract}
Background/objectives: Type 2 diabetes (T2D) is a global pandemic, and contributes significantly to the increasing incidence of conditions such as cardiovascular disease (CVD). Postprandial plasma glucose measured 2-h after the start of a meal is a good indicator of the overall status of glucose homeostasis. Clove (Syzygium aromaticum L.) and its essential oils (eugenol and acetyl eugenol) have been shown in preclinical studies to modulate pathways involved in glucose homeostasis. In addition, a water-soluble polyphenolic extract of unopened clove buds was recently shown to benefit liver function and redox status. Therefore, we conducted an open-label pilot study to test whether this polyphenolic clove extract (PCE) could influence glucose metabolism.
\end{abstract}

Methods: We evaluated the effect of PCE supplementation (250 mg once daily for 30 days) on preprandial glucose levels and 2-h postprandial glucose levels in 13 otherwise healthy volunteers who were stratified into two groups according to their initial preprandial glucose levels: Group I $(n=7) \leq 100 \mathrm{mg} / \mathrm{dL}$, Group II $(n=6)$ - between 101 and $125 \mathrm{mg} / \mathrm{dL}$. In an effort to elucidate the molecular mechanisms of PCE action, we tested in vitro the effects of PCE on glucose uptake, hepatocyte glucose production, and carbohydrate hydrolyzing enzymes.

Results: At day 12 of supplementation, we observed statistically significant reductions in mean postprandial glucose levels in both groups [(Group I: Initial - Day 12 PPG $=13.29$ mg/dL, 95\% Cl: 3.329-23.24) (Group II: Initial Day $12 \mathrm{PPG}=16.67 \mathrm{mg} / \mathrm{dL}, 95 \% \mathrm{Cl}: 4.687-28.65, P=0.0159)]$, which continued through study completion at day 30. PCE supplementation significantly decreased mean preprandial glucose levels only in Group II at Days 24 (Initial - Day $24=13.00 \mathrm{mg} / \mathrm{dL}, 95 \% \mathrm{Cl}: 1.407-24.59, P=0.0345)$ and 30 (Initial - Day $30=13.67 \mathrm{mg} / \mathrm{dL}$, 95\% Cl: 5.766-21.57, $P=0.0067)$. In cell-based assays, PCE enhanced glucose uptake in L6 myocytes and inhibited hepatocyte glucose production HepG2 cells. In cell-free assays, PCE inhibited a-amylase activity and a-glucosidase activity.

Conclusions: These findings underscore the therapeutic utility of PCE for maintaining healthy glucose metabolism and warrant further larger-scale clinical trials.

Trial registration: This trial was retrospectively registered in the ISRCTN registry on September 29, 2018 (ISRCTN15680985).

\footnotetext{
* Correspondence: Krishnakumar.IM@akay-group.com

${ }^{2}$ R\&D center, Akay Flavours \& Aromatics Pvt Ltd, Cochin, India

Full list of author information is available at the end of the article
}

(c) The Author(s). 2019 Open Access This article is distributed under the terms of the Creative Commons Attribution 4.0 International License (http://creativecommons.org/licenses/by/4.0/), which permits unrestricted use, distribution, and reproduction in any medium, provided you give appropriate credit to the original author(s) and the source, provide a link to the Creative Commons license, and indicate if changes were made. The Creative Commons Public Domain Dedication waiver (http://creativecommons.org/publicdomain/zero/1.0/) applies to the data made available in this article, unless otherwise stated. 


\section{Background}

Type 2 diabetes is a tremendous public health issue. More than $75 \%$ of the US population over 65 years of age has some degree glucose homeostasis dysfunction [1]. In 2014, adults 25 to 44 years of age were more than twice as likely to have diabetes and be overweight or obese than in 1989 [2]. Factors driving this metabolic syndrome pandemic include alterations in diet and reduced physical activity [3]. Diets have shifted from nutrient-dense (fresh vegetables and fruits, and unrefined grains) to energy-rich but nutrient-poor (refined grains, sugars and fats) [4]. Numerous population studies across the globe have demonstrated that polyphenol intake has an inverse relationship with disease incidence [5-7]. And, diets low in polyphenols are associated with an increase in T2DM incidence [8-10]. PCE is a water-soluble standardized extract of unopened clove (Syzygium aromaticum L.) buds that contains a minimum of $30 \%$ total polyphenols [11-13]. HPLC analysis of PCE revealed the presence of gallic acid, ellagic acid, catechin, quercetin, chlorogenic acid, and eugenol [12].

The liver plays a major role in maintaining ideal levels of glucose throughout the body by regulating de novo glucose production (gluconeogenesis) and glycogen breakdown (glycogenolysis) [14]. Dysregulated and exaggerated hepatic glucose production (HGP) can result in poor clinical outcomes and is a major contributor to impaired glucose homeostasis and type 2 diabetes [14]. Supporting the idea that insulin resistance originates in liver tissue, a preclinical model of diet-induced obesity demonstrated that insulin resistance was first detected in the liver, then in white adipose tissue [15].

Our earlier preclinical and clinical studies demonstrated beneficial effects of PCE on liver function, antioxidant status, and metabolism of alcohol [11, 12, 16]. We thus hypothesized that, since the liver plays a crucial role in the pathogenesis of insulin resistance and diabetes, PCE could have a beneficial effect on glucose metabolism as well. We tested the effects that daily supplementation with PCE has on preprandial and postprandial blood glucose levels in an open-label pilot study. We also used a series of in vitro assays to elucidate PCE's mechanism of action on glucose metabolism.

\section{Materials and methods}

\section{Clinical study design}

The clinical study protocol was reviewed approved by an independent ethics committee (Reg. No: ECR/184/Indt/ $\mathrm{KA} / 2014)$. We evaluated the effect of PCE $(250 \mathrm{mg} \times 1$; hard shell, two-piece gelatin capsule) on the preprandial and postprandial plasma glucose levels of 13 volunteers (10 males and 3 females, aged 25 to 35 years). We grouped the subjects according to their initial plasma glucose levels. Group I had pre-lunch plasma glucose levels $\leq 100 \mathrm{mg} / \mathrm{dL}$; Group II had levels between 101 and $125 \mathrm{mg} / \mathrm{dL}$. We asked all subjects to complete their breakfast by $8 \mathrm{AM}$ and not to consume any food or snacks for another $4 \mathrm{~h}$ (until 12 noon). The subjects had ad libitum water access. We measured subjects' blood sugar levels with a digital glucometer at 12:00 PM and marked this sample as the "preprandial" plasma glucose level. Subjects then consumed a typical south-Indian lunch with rice, vegetable curry with meat or fish, and water within $30 \mathrm{~min}$. We provided one capsule of PCE to each subject immediately after lunch. After $2 \mathrm{~h}$, we measured subjects' plasma glucose levels again and marked the sample as "postprandial." This routine continued for 30 days, and we recorded preprandial and postprandial glucose levels on days 1, 12, 24 and 30. Day 1 was "without PCE" and it is taken as the baseline value. Throughout the study and analysis, no investigators were blinded.

\section{Clinical study participants}

All volunteers provided written informed consent before the study. The subjects were generally healthy and did not take any regular medication. Physical activity levels were similar among the participants. We advised the participants to follow their normal south-Indian food pattern, which typically consists of: breakfast made of rice (having an approximate nutritional composition of fat: 22 to $24 \%$, carbohydrates: 35 to $40 \%$, protein: 27 to $30 \%$; energy 400 to $500 \mathrm{cal}$ ), lunch with rice and vegetable/non-vegetable curries (having an approximate nutritional composition of fat: 25 to $30 \%$, carbohydrates: 35 to $42 \%$, protein: 32 to $35 \%$; energy 500 to $580 \mathrm{cal}$ ), and dinner with similar nutritional compositions to lunch.

\section{Clinical study material}

As described previously, we prepared PCE by the hydro-ethanolic extraction of dried clove buds followed by low temperature evaporation and spray drying to free flowing powder with not less than $30 \%$ polyphenols as gallic acid equivalent [11-13].

\section{Glucose uptake assay}

We conducted the glucose uptake assay according to the protocol described by Yap et al., 2007 [17]. We purchased L6 rat myoblast cells from NCCS Pune and maintained them in Dulbecco's modified eagles media (Sigma Aldrich, USA) supplemented with 10\% FBS (Invitrogen) and grew them to $80 \%$ confluency at $37{ }^{\circ} \mathrm{C}$ in $5 \% \mathrm{CO}_{2}$ in a humidified atmosphere in a $\mathrm{CO}_{2}$ incubator (NBS, Eppendorf, Germany). We detached cells with trypsin $[500 \mu \mathrm{L}$ of $0.025 \%$ Trypsin in PBS/0.5 mM EDTA solution (Invitrogen)] for $2 \mathrm{~min}$ then passaged them to T-75 flasks in complete aseptic conditions. We then subcultured the cells to a 24-well plate. After the cells 
attained 80\% confluency, we kept them in DMEM without glucose for $24 \mathrm{~h}$. We then added extracts to grown cells at a final concentration of $25 \mu \mathrm{g}, 50 \mu \mathrm{g}$, and $100 \mu \mathrm{g}$ from a stock of $1 \mathrm{mg} / \mathrm{mL}$ and incubated them for $24 \mathrm{~h}$ in DMEM containing $300 \mathrm{mM}$ glucose. We also maintained an untreated control with high glucose. After incubation, we isolated the cells by spinning them at $6000 \mathrm{rpm}$ for $10 \mathrm{~min}$. We then discarded the supernatant and added $200 \mu \mathrm{L}$ of cell lysis buffer $(1 \mathrm{M}$ Tris $\mathrm{HCl}, 0.25 \mathrm{M}$ EDTA, $2 \mathrm{M} \mathrm{NaCl}, 0.5 \%$ Triton). The incubation period was 30 min at $37^{\circ} \mathrm{C}$, and we estimated the glucose uptake using a high-sensitivity glucose oxidase kit (Glucose oxidase kit, Erba). We repeated all experiments in triplicates and used mean average to calculate percent glucose uptake relative to untreated controls.

\section{Endogenous glucose production assay}

We conducted the glucose production assay according to the protocol described by Caton et al., 2010 [18]. We purchased HepG2 cells from NCCS Pune and maintained them in Dulbecco's modified eagles media (Sigma Aldrich) supplemented with 10\% FBS (Invitrogen) and grew them to $80 \%$ confluency at $37^{\circ} \mathrm{C}$ in $5 \% \mathrm{CO}_{2}$. We next subcultured the cells to a 24-well plate. After the cells attained $80 \%$ confluency, we kept them in DMEM without glucose and treated them with PCE at final concentrations of $25 \mu \mathrm{g} / \mathrm{mL}, 50 \mu \mathrm{g} / \mathrm{mL}$, or $100 \mu \mathrm{g} / \mathrm{mL}$ for $30 \mathrm{~min}$ and incubated them for $6 \mathrm{~h}$ after adding $100 \mathrm{nM}$ glucagon. We also maintained controls (i.e., without PCE) under similar conditions. After incubation, we isolated the cells by spinning them at $6000 \mathrm{rpm}$ for $10 \mathrm{~min}$. We then discarded the supernatant and added $200 \mu \mathrm{L}$ of cell lysis buffer $(1 \mathrm{M}$ Tris $\mathrm{HCl}, 0.25 \mathrm{M}$ EDTA, $2 \mathrm{M} \mathrm{NaCl}$, $0.5 \%$ Triton). The incubation period was $30 \mathrm{~min}$ at $37^{\circ} \mathrm{C}$, and we estimated the glucose content using a glucose-kit method (Erba Mannheim, Germany) and read absorbance at $505 \mathrm{~nm}$ (Agilent, USA). We repeated all experiments in triplicates and used the mean average to calculate the percent glucose production relative to untreated controls.

\section{a-Glucosidase inhibition assay}

We measured $\alpha$-glucosidase activity in a cell-free assay by determining the reducing sugars formed upon hydrolysis of sucrose by $\alpha$-glucosidase enzyme. We determined the effect of PCE on $\alpha$-glucosidase activity according to the method described by Matsui and colleagues [19], with slight modifications. Briefly, we pre-incubated $1 \mathrm{mg} \quad \alpha$-glucosidase protein (Sigma Aldrich) with different concentrations of PCE for $5 \mathrm{~min}$ at $37^{\circ} \mathrm{C}$. Then, we added the substrate sucrose $(37 \mathrm{mM})$, and brought the final reaction mixture to $1 \mathrm{~mL}$ with 0.1 $\mathrm{M}$ phosphate buffer ( $\mathrm{pH}$ 7.2). We incubated the reaction mixture for $30 \mathrm{~min}$ at $37^{\circ} \mathrm{C}$ then stopped the reaction by incubating the mixture in a boiling water bath for $2 \mathrm{~min}$.
We maintained a tube treated with phosphate buffer and enzyme as a control. Next, we added $250 \mu \mathrm{L}$ of glucose reagent (Glucose oxidase kit, Erba) to each tube and incubated them for $10 \mathrm{~min}$ before measuring absorbance at $510 \mathrm{~nm}$. The $\alpha$-glucosidase inhibitory activity is expressed as percentage of inhibition relative to untreated controls.

\section{a-Amalyase inhibition assay}

We performed this assay according to the method developed by Bernfeld in 1955 [20]. We pre-incubated different concentrations of PCE with $25 \mu \mathrm{L}$ of porcine $\alpha$-amylase $(0.5 \mathrm{mg} / \mathrm{mL})$ at $25^{\circ} \mathrm{C}$ for $10 \mathrm{~min}$. After pre-incubation, we added $25 \mu \mathrm{L}$ of $0.5 \%$ starch solution in $25 \mathrm{mM}$ phosphate buffer (pH 6.9). We then incubated the reaction mixtures at $25^{\circ} \mathrm{C}$ for $10 \mathrm{~min}$. We maintained enzyme preparations treated with PBS under the same conditions as controls. We stopped the reaction with $50 \mu \mathrm{L}$ of $96 \mathrm{mM}$ 3,5-dinitrosalicylic acid color reagent. We then incubated the micro-plate in a boiling water bath for $5 \mathrm{~min}$ and cooled it to room temperature. We measured absorbance at $540 \mathrm{~nm}$ using a microplate reader (Erba, Lisascan). The $\alpha$-amalyase inhibitory activity is expressed as percentage of inhibition relative to untreated controls.

Table 1 Pilot study statistics

\begin{tabular}{llll}
\hline Comparison & $\begin{array}{l}\Delta \text { Plasma Glucose } \\
\text { (mg/dL) }\left[\begin{array}{l}\text { Initial - Day }] \\
\text { Interval }\end{array}\right.\end{array}$ & $\begin{array}{l}P \\
\text { Value }\end{array}$ \\
\hline Group I Preprandial & & \\
Initial vs. Day 12 & 1.286 & $-5.752-8.324$ & 0.6705 \\
Initial vs. Day 24 & 2.000 & $-3.150-7.150$ & 0.3786 \\
Initial vs. Day 30 & 4.857 & $-2.032-11.75$ & 0.1352 \\
Group II Preprandial & & \\
Initial vs. Day 12 & 0.5000 & $-6.764-7.764$ & 0.8665 \\
Initial vs. Day 24 & 13.00 & $1.407-24.59$ & $\mathbf{0 . 0 3 4 5}$ \\
Initial vs. Day 30 & 13.67 & $5.766-21.57$ & $\mathbf{0 . 0 0 6 7}$ \\
Group I Postprandial & & \\
Initial vs. Day 12 & 13.29 & $3.329-23.24$ & $\mathbf{0 . 0 1 7 1}$ \\
Initial vs. Day 24 & 17.29 & $0.9953-33.58$ & $\mathbf{0 . 0 4 0 9}$ \\
Initial vs. Day 30 & 27.00 & $3.378-50.62$ & $\mathbf{0 . 0 3 1 3}$ \\
Group II Postprandial & & \\
Initial vs. Day 12 & 16.67 & $4.687-28.65$ & $\mathbf{0 . 0 1 5 9}$ \\
Initial vs. Day 24 & 30.50 & $3.726-57.27$ & $\mathbf{0 . 0 3 2 7}$ \\
Initial vs. Day 30 & 40.33 & $15.23-65.43$ & $\mathbf{0 . 0 0 9 1}$ \\
\hline
\end{tabular}

We compared preprandial and postprandial plasma glucose levels taken at each time point to initial values and calculated statistical significance using a paired t-test in GraphPad Prism 5.0 software. Mean change in plasma glucose, 95\% confidence interval, and $P$ value are shown for each time point as compared to initial values, with $P \leq 0.05$ in bold text 
Table 2 In vitro study statistics

\begin{tabular}{|c|c|c|c|}
\hline $\mathrm{IC}_{50}$ & Standard Error & 95\% Confidence Interval & $R^{2}$ \\
\hline \multicolumn{4}{|c|}{ Glucose Production } \\
\hline $63.80 \mu \mathrm{g} / \mathrm{mL}$ & 0.0632 & $45.22-90.01$ & 0.7192 \\
\hline \multicolumn{4}{|c|}{ a-Glucosidase Activity } \\
\hline \multicolumn{4}{|l|}{ PCE } \\
\hline $60.84 \mathrm{mg} / \mathrm{mL}$ & 0.0283 & $52.84-70.05$ & 0.9523 \\
\hline \multicolumn{4}{|l|}{ Acarbose } \\
\hline $40.28 \mathrm{mg} / \mathrm{mL}$ & 0.0276 & $35.00-46.21$ & 0.9568 \\
\hline \multicolumn{4}{|c|}{ a-Amylase Activity } \\
\hline $51.63 \mu \mathrm{g} / \mathrm{mL}$ & 13.29 & $45.39-58.71$ & 0.9615 \\
\hline
\end{tabular}

For the inhibitory action that PCE has on glucose production and carbohydrate hydrolyzing enzymes, we calculated the $\mathbb{I}_{50}$ values using the log (inhibitor) vs. response equation with variable slope in GraphPad Prism 5.0 software. Standard error, $95 \%$ confidence intervals, and goodness of curve fitting $\left(R^{2}\right)$ are shown

\section{Statistical analysis}

We used GraphPad Prism 5.0 software to analyze all of the data. For the pilot study, we used a paired, two-tailed t-test to detect significant differences between glucose levels recorded at each time point and those collected at baseline. We calculated mean differences, 95\% confidence intervals and $P$ values, which are tabulated in Table 1. For in vitro experiments, we used the non-linear regression log (inhibitor) vs response equation with variable slope to calculate the $\mathrm{IC}_{50}$ values. We tabulated standard error, 95\% confidence intervals, and goodness of curve fitting $\left(R^{2}\right)$ in Table 2 .

\section{Results}

Figure 1 shows the open-label trial design. On the initial day of the trial, 13 subjects were assigned to one of two groups based on their preprandial blood glucose levels tested just before lunch $4 \mathrm{~h}$ after breakfast (Fig. 1). Group I consisted of 7 individuals with preprandial blood glucose $\leq 100 \mathrm{mg} / \mathrm{dL}$, and Group II was comprised of individuals with preprandial glucose between 101 and $125 \mathrm{mg} / \mathrm{dL}$ (Fig. 1). The study material, PCE, was supplied in one gelatin capsule at $250 \mathrm{mg} /$ capsule. On trial days 2-30, subjects took one PCE capsule immediately after finishing lunch. Preprandial and 2-h postprandial glucose measurements were taken on days $1,12,24$, and 30 of the study.

For Group I, PCE supplementation did not alter preprandial glucose levels throughout the duration of the study (Fig. 2a-b; Table 1). However, in Group II significant decreases in preprandial glucose levels manifested on day 24 and continued to study completion (Fig. 2c-d; Table 1). The mean preprandial glucose level in Group II fell by $12 \%$ from baseline $114.2 \pm 2.54 \mathrm{mg} / \mathrm{dL}$ [mean \pm $\mathrm{SD}$ ] to day 30; $100.5 \pm 2.68 \mathrm{mg} / \mathrm{dL}$ [mean $\pm \mathrm{SD}$ ] (Fig. 2d; Table 1). These results indicate that PCE is unlikely to cause hypoglycemia as preprandial glucose was not affected in individuals whose levels were initially within a normal range of less than $100 \mathrm{mg} / \mathrm{dL}$ (Fig. 2a-b; Table 1), but decreased in individuals who displayed tendencies of abnormal glucose homeostasis (Fig. 2c-d; Table 1). Since PCE was administered once daily after lunch, the reduction in preprandial glucose levels in Group II suggests that PCE is effective at maintaining normal blood glucose levels throughout the day in individuals with tendencies of abnormal glucose homeostasis. Taken together, these data demonstrate the efficacy of once daily PCE supplementation at managing glucose homeostasis throughout the day.

PCE supplementation controlled postprandial glucose levels in both groups (Fig. 3). For Groups I and II, significant reductions in 2-h post-prandial glucose levels were seen at the earliest time point, day 12, and continued throughout the study (Fig. $3 \mathrm{a}$ and $\mathrm{c}$; Table 1). In Group I, the postprandial baseline value was $125.4 \pm$ $8.82 \mathrm{mg} / \mathrm{dL}$ (mean $\pm \mathrm{SD}$ ), and by day 30 PCE supplementation significantly reduced this value by $21.5 \%$ to 98.43

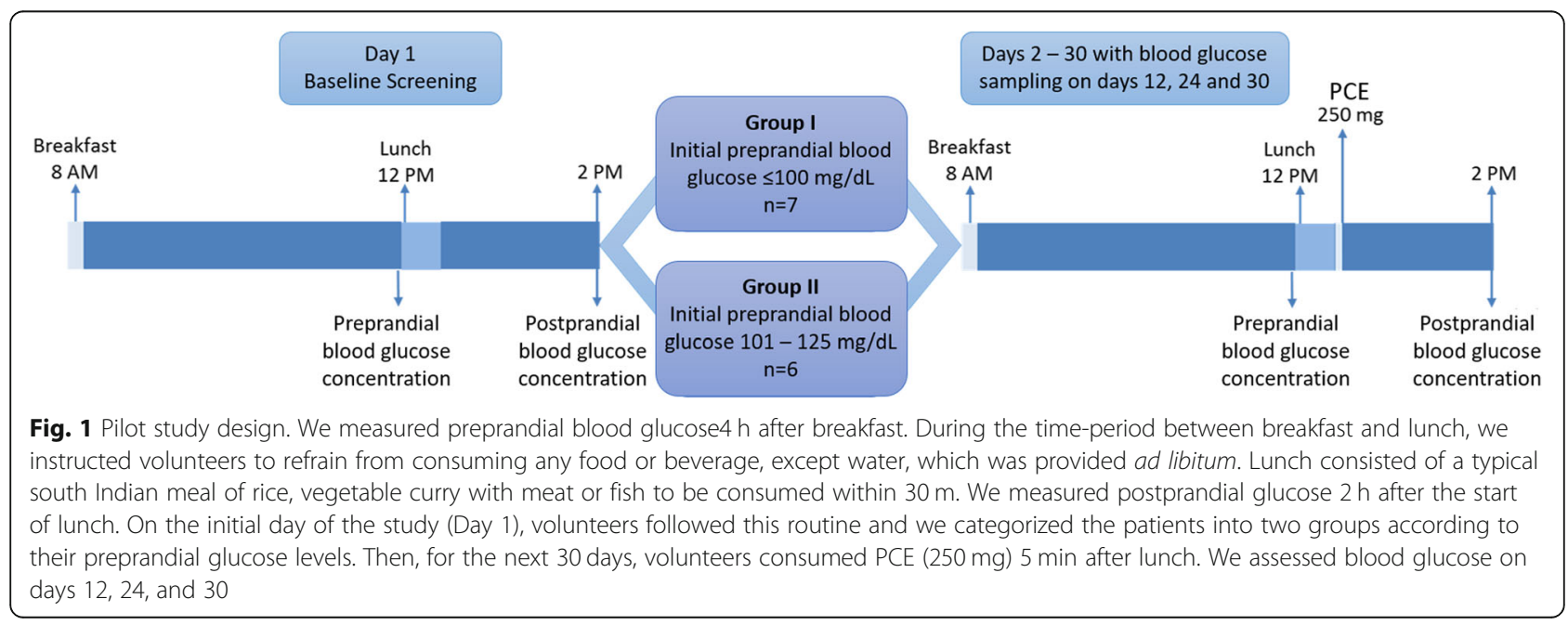




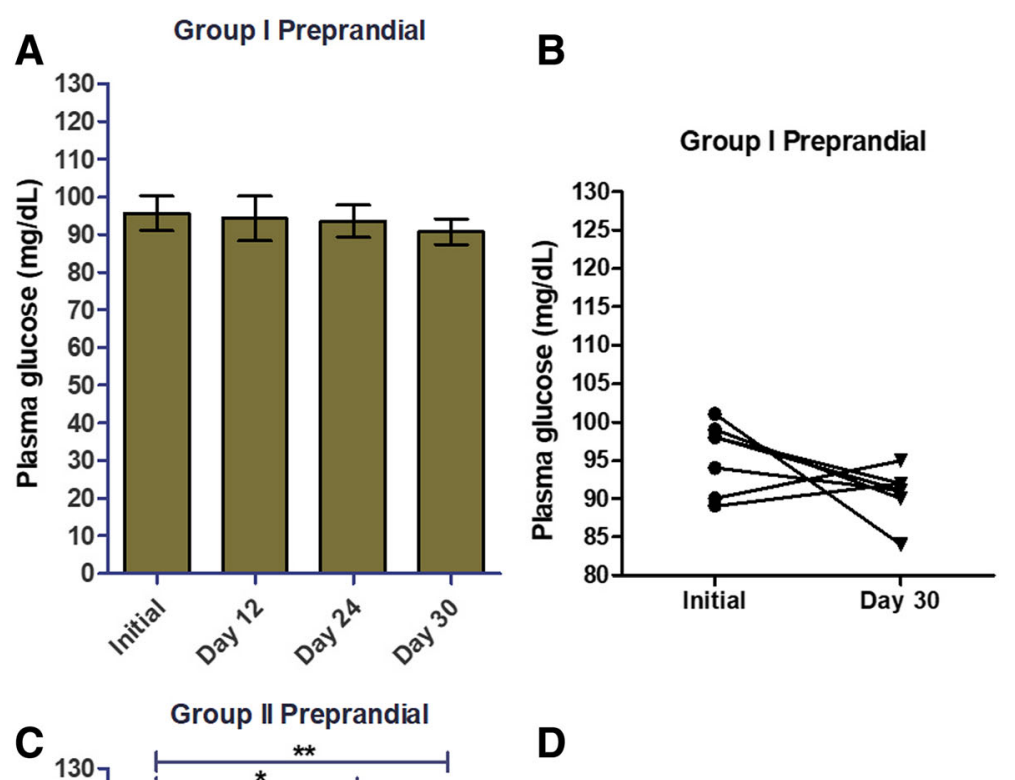

Group II Preprandial
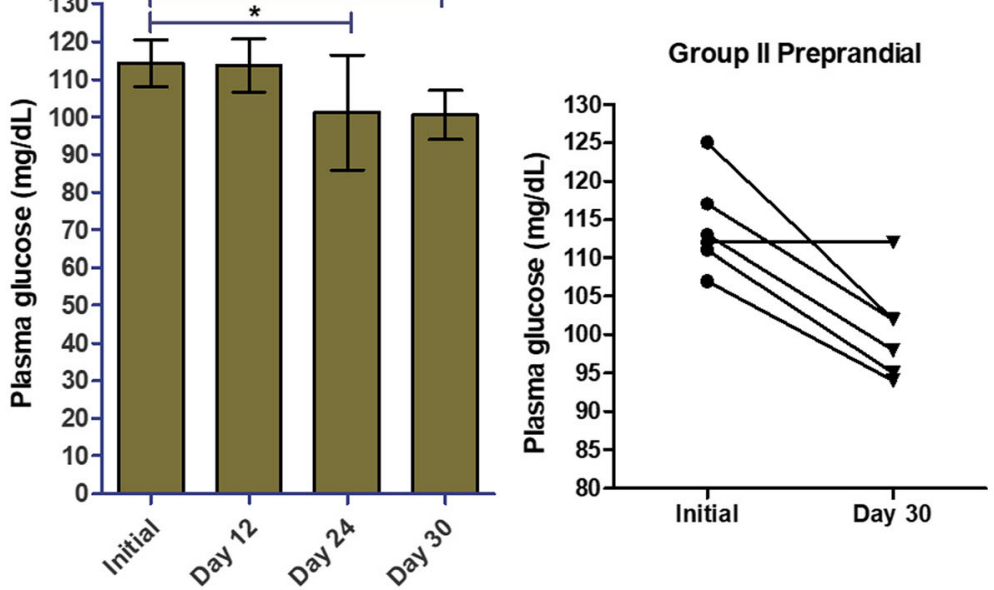

Fig. 2 PCE supplementation reduces preprandial glucose levels in the prediabetes group, but not in the group with blood glucose already within normal range. On the initial day of the study, we divided individuals into two groups based on their preprandial (before lunch) plasma glucose levels: a-b, Group I, $\leq 100 \mathrm{mg} / \mathrm{dL}$; c-d, Group II, 101-125 mg/dL. Pre-prandial plasma glucose levels were measured and recorded on days 1 (initial), 12, 24, and $30(\mathbf{a}, \mathbf{c})$. We plotted individual study subject plasma glucose levels for the initial day and day 30 of the study (b, d). Data shown are mean \pm SD for $\mathbf{a}$ and $\mathbf{c}$. We calculated statistical significance $\left({ }^{*}, p \leq 0.05 ;{ }^{* *}, p \leq 0.01\right)$ by comparing glucose levels measured at each time point to the initial value using a two-tailed t-test in GraphPad Prism 5.0 software

$\pm 1.49 \mathrm{mg} / \mathrm{dL}$ (mean \pm SD) (Fig. 3b; Table 1). There was a more pronounced effect on postprandial glucose in Group II: PCE significantly reduced postprandial glucose by $27.2 \%$ from $148.3 \pm 11.88 \mathrm{mg} / \mathrm{dL}$ (mean $\pm \mathrm{SD}$ ) at baseline to $108 \pm 3.86 \mathrm{mg} / \mathrm{dL}$ (mean $\pm \mathrm{SD}$ ) at day 30 (Fig. 3d; Table 1 ). These results clearly support the rationale for once daily PCE supplementation to promote healthy glucose metabolism, in particular, post-prandial glucose.

Next, we carried out in vitro assays to elucidate the molecular mechanism(s) by which PCE lowers glucose (Fig. 4). In this first set of in vitro experiments, we assessed glucose uptake in L6 myotubes in the absence or presence of increasing PCE concentrations. We found that PCE dose-dependently enhanced glucose uptake in this cell model (Fig. 4a). PCE concentrations of 25, 50 and $100 \mu \mathrm{g} / \mathrm{mL}$ increased glucose uptake by 46.97 , 50.02 and $63.36 \%$ over untreated controls, respectively (Fig. 4a). This finding suggests that PCE could be increasing insulin sensitivity to lower plasma glucose as observed in Figs. 2 and 3.

Then, we investigated the effects of PCE on endogenous glucose production in hepatocytes, which is arguably one of the most important sites for controlling postprandial plasma glucose. Briefly, we incubated glucose-starved HepG2 cells with glucagon (to stimulate gluconeogenesis and glycogenolysis) in the presence or absence of increasing concentrations of PCE. In a concentration-dependent manner, PCE inhibited hepatocyte glucose production 


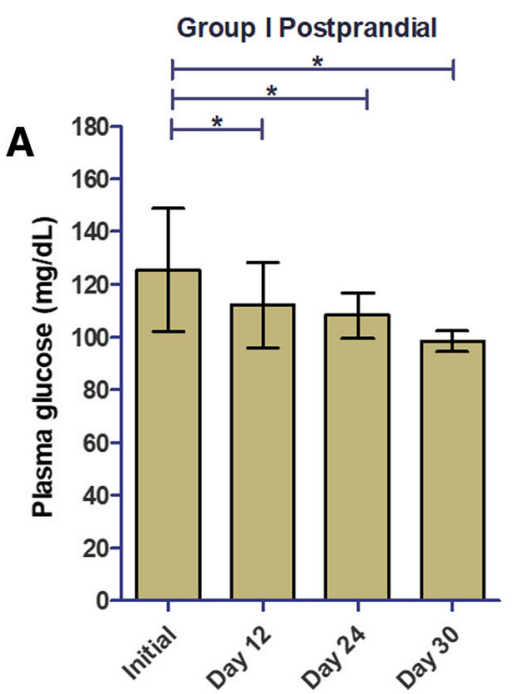

B
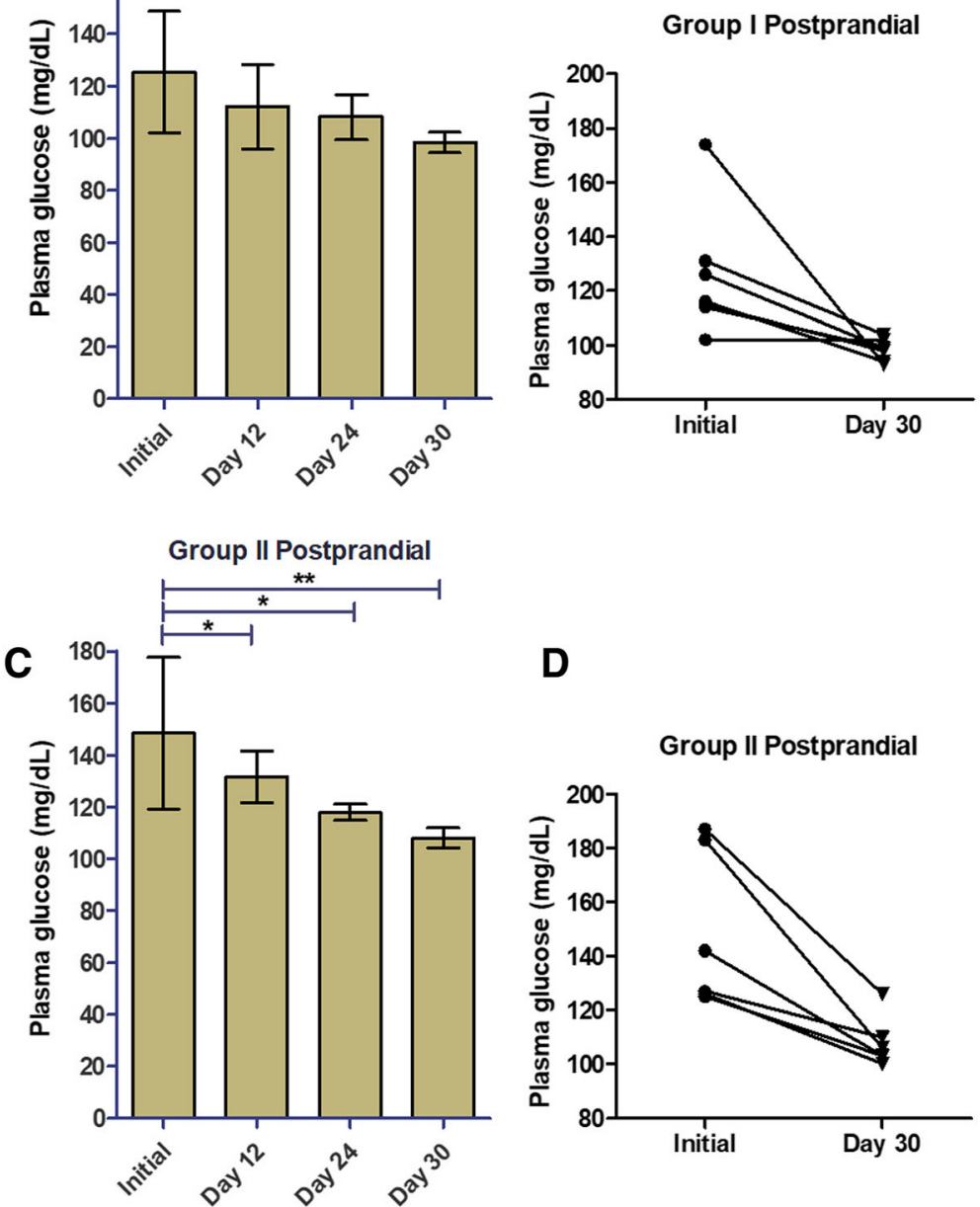

D

Group II Postprandial

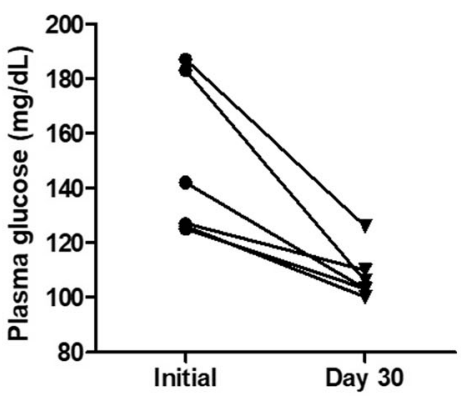

Fig. 3 In both normal and prediabetic individuals, PCE supplementation decreased postprandial blood glucose. After the initial day of the study, subjects consumed one PCE capsule immediately after finishing lunch each day for the duration of the study and postprandial glucose was measured $2 \mathrm{~h}$ after the start of lunch. Postprandial plasma glucose levels were measured and recorded on days 1 (initial), 12, 24, and 30 (a, c). We plotted individual study subject plasma glucose levels for the initial day and day 30 of the study (b, d). Data shown are mean \pm SD for $\mathbf{a}$ and $\mathbf{c}$. We calculated statistical significance $\left({ }^{*}, p \leq 0.05 ;{ }^{* *}, p \leq 0.01\right)$ by comparing glucose levels measured at each time point to the initial value using a two-tailed t-test in GraphPad Prism 5.0 software

with an $\mathrm{IC}_{50}$ of $63.8 \mu \mathrm{g} / \mathrm{mL}$ (Fig. 4; Table 2). This finding is consistent with the results of a previous study that identified a eugenol-depleted hydroethanolic clove extract inhibited glycogen phosphorylase b $\left(\mathrm{IC}_{50}=0.86 \mu \mathrm{g} / \mathrm{mL}\right)$, the enzyme responsible for converting liver glycogen to glucose [21]. This PCE mechanism likely accounts for the marked improvements in postprandial plasma glucose observed in our study participants (Figs. 2c-d; 3c-d), but especially Group II (Fig. 3c-d).

In the next set of in vitro experiments, we tested the ability of PCE to inhibit key carbohydrate hydrolyzing enzymes, $\alpha$-amylase and $\alpha$-glucosidase, in cell-free assays. PCE dose-dependently inhibited both enzymes
(Fig. 4c-d; Table 2). The efficacy of PCE at inhibiting $\alpha$-glucosidase activity with an $\mathrm{IC}_{50}$ of $60.84 \mathrm{mg} / \mathrm{mL}$ was similar to that of the antidiabetic drug acarbose, which has an $\mathrm{IC}_{50}$ of $40.28 \mathrm{mg} / \mathrm{mL}$ at this enzyme (Fig. 4c; Table 2). PCE was more efficacious at inhibiting $\alpha$-amylase with an $\mathrm{IC}_{50} 42.87 \mu \mathrm{g} / \mathrm{mL}$ (Fig. 4d; Table 2).

\section{Discussion}

Although fasting plasma glucose is the traditional standard for diabetes screening, impaired glucose tolerance (IGT) may be present in individuals with normal fasting glucose. And IGT may have a slightly stronger association with cardiovascular risk than IFG alone [22]. 

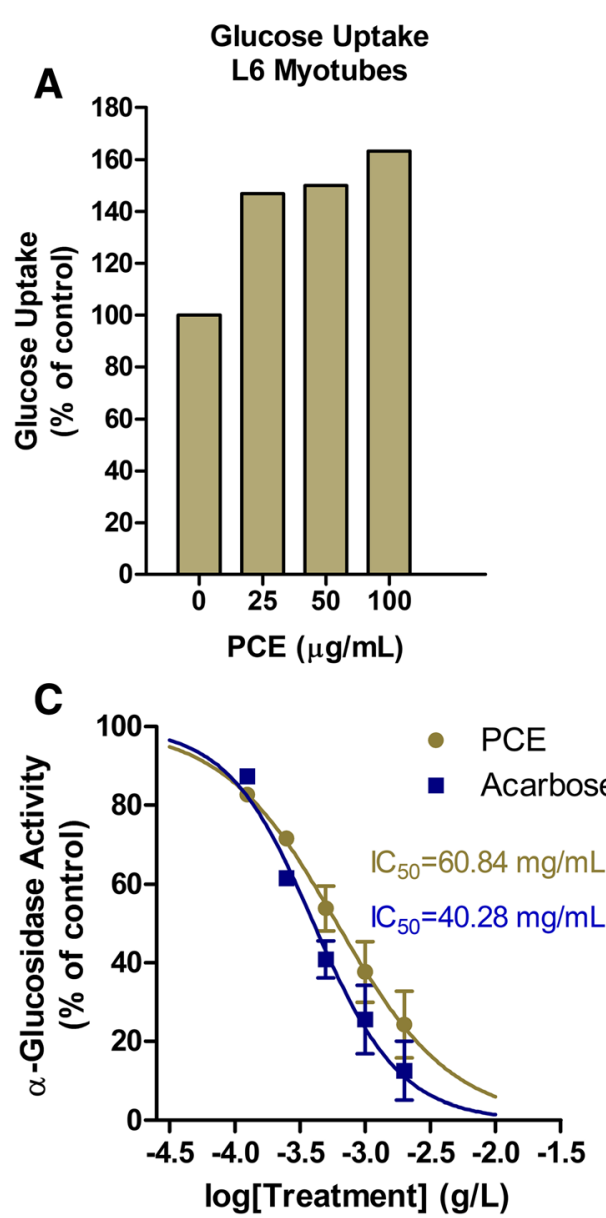

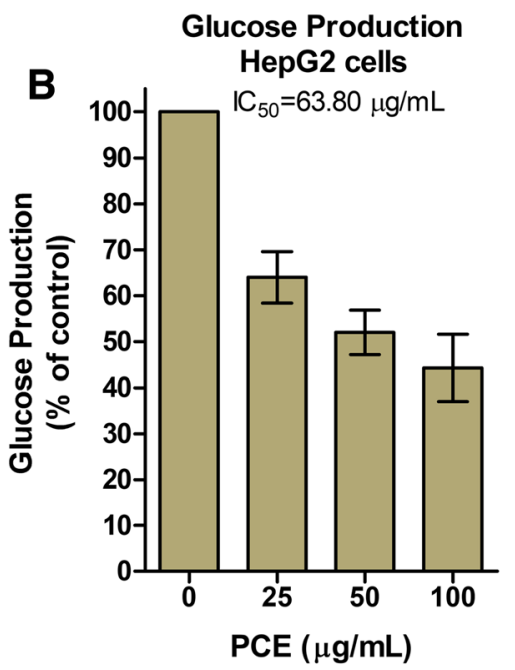

D

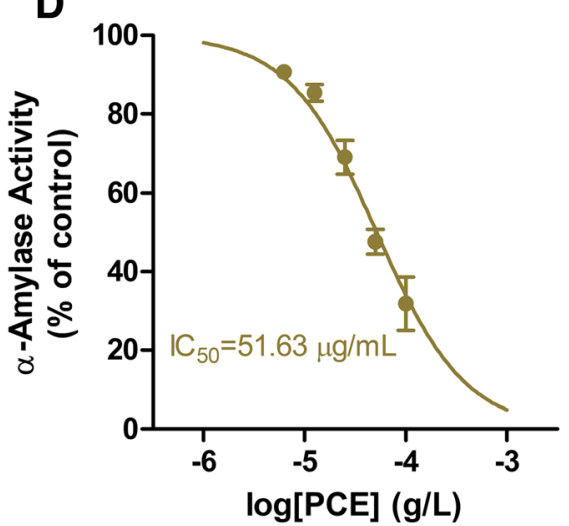

Fig. 4 In vitro effects of PCE on key aspects of glucose homeostasis. (a) Glucose uptake in L6 myotubes in the absence or presence of increasing concentrations of PCE. (b) Hep2G cell endogenous glucose production in the absence or presence of increasing concentrations of PCE. (c-d) Concentration-response curve for PCE (O) and Acarbose ( $)$ mediated inhibition of a-glucosidase (c) and a-amalyase enzyme activity (d) in cell-free systems. All data are represented as mean \pm SD percent activity relative to untreated controls. We derived $I C_{50}$ values and fit curves using a non-liner inhibitory concentration-response equation with variable slope in GraphPad Prism 5.0 software

Hemoglobin $\mathrm{A}_{1 \mathrm{c}}\left(\mathrm{HbA}_{1 \mathrm{c}}\right)$ is a measure of the degree to which hemoglobin is glycosylated in erythrocytes and is expressed as a percentage of total hemoglobin concentration [23]. It reflects the exposure of erythrocytes to glucose in an irreversible and time- and concentration-dependent manner [23]. $\mathrm{HbA}_{1 \mathrm{c}}$ levels provide an indication of the average blood glucose concentration during the preceding 2-3 months, incorporating both pre- and post-prandial glycemia. While $\mathrm{HbA}_{1 \mathrm{c}}$ is an indicator of long-term glucose homeostasis, it may not reflect the magnitude of acute glucose spikes during the postprandial period [23]. Moreover, clinically significant inter-subject variability exists and $\mathrm{HbA}_{1 \mathrm{c}}$ measurements inadequately reflect actual glycemic control for many patients [24].

Several studies have highlighted the correlation between postprandial blood glucose and cardiovascular events and mortality [25-32]. In aged type 2 diabetics, exaggerated PPG excursions are associated with impaired cognitive function [33]. Therapies that target PPG excursions have demonstrated their utility in the clinic [34]. Thus, interventions that delay or prevent postprandial hyperglycemia could be significantly useful in curbing the impaired glucose homeostasis pandemic.

Glucose metabolism is a tightly regulated process. After eating, $\alpha$-amylase and $\alpha$-glucosidase enzymes digest carbohydrates into simple sugars. This excursion of glucose into the bloodstream stimulates secretion of insulin from pancreatic $\beta$-cells, while attenuating secretion of glucagon from $\alpha$-cells. Insulin signaling promotes glucose uptake into peripheral sites in the body where it serves as an energy source. Skeletal muscle and liver are particularly important sites of energy storage. Excess glucose, stored as glycogen, in liver and skeletal muscle is utilized during periods of vigorous activity or fasting via glucagon signaling. Once glycogen stores in muscle 
and liver reach full capacity, excess glucose is then stored as fat. Thus, maintaining optimal glucose metabolism hinges upon insulin secretion from the pancreas and sensitivity of peripheral tissue to insulin.

The marked decrease in postprandial glucose levels we observed in the pilot study could be attributed to a decrease in hepatic glucose production. Our in vitro data supports this hypothesis as PCE inhibited hepatocyte glucose production with an $\mathrm{IC}_{50}$ of $63.8 \mu \mathrm{g} / \mathrm{mL}$ (Fig. 4b; Table 2). In another study using a cell-free assay, a polyphenol-rich clove extract inhibited glycogen phosphorylase b $\left(\mathrm{IC}_{50}=\right.$ $0.86 \mu \mathrm{g} / \mathrm{mL}$ ), the enzyme responsible for converting liver glycogen to glucose [21]. One can speculate that our PCE may be inhibiting glycogen phosphorylase b, although further testing is needed to confirm this hypothesis.

\section{Conclusion}

Taken together, the results of the present study indicate that PCE potentially works through multiple molecular mechanisms to control glucose homeostasis. This is apparent in the clinical study results where significant changes in postprandial blood glucose were observed at the first time point in both groups (Fig. 3), but preprandial blood glucose changes were not recorded until later in the study and only in the group that had higher baseline levels, Group II (Fig. 2). The early changes in postprandial blood glucose can likely be attributed to PCE's inhibitory effects on $\alpha$-glucosidase and $\alpha$-amylase enzymes. It stands to reason that the continued improvement in postprandial blood glucose over time in both groups could involve increased insulin sensitivity and decreased hepatic glucose production. Similarly, the full effects of metformin on blood sugar can take up to 4-6 weeks to be seen, and metformin increases insulin sensitivity in liver and muscle [35]. Its action on liver results in decreased hepatic glucose production, which is arguably one of the most important sites for controlling plasma glucose. These positive results of PCE on glucose homeostasis control warrant further investigation into its therapeutic utility as a treatment option delaying and/or preventing the transition from pre-diabetes to type 2 diabetes.

\section{Abbreviations}

CVD: Cardiovascular disease; $\mathrm{HbA}_{1}$ : Hemoglobin $\mathrm{A}_{1 c}$; HGP: Hepatic glucose production; IGT: Impaired glucose tolerance; PCE: Polyphenolic clove extract; PPG: Postprandial glucose; T2D: Type 2 diabetes mellitus

\section{Acknowledgements}

The authors would like to thank Dr. Balu Maliakel for advice on the development of the study protocol and Blake Gossard for critical review and editing.

\section{Funding}

The authors are grateful to M/s Akay Flavours \& Aromatics Ltd., Cochin, India for the financial support under the development program of Spiceuticals ${ }^{\circledast}$.
Availability of data and materials

The datasets used and/or analyzed during the current study are available from the corresponding author on reasonable request.

\section{Authors' contributions \\ Experimental design was done by IMK and JM, experiments and data collection were done by RM and SPJ, data analysis was done by IMK, DKS and AGS, and manuscript preparation and review were done by IMK, DKS and AGS. All authors read and approved the final manuscript.}

\section{Ethics approval and consent to participate}

This study was reviewed and approved by the independent Ethics Committee of Sri Rama Hospital (ECR/184/Indt/KA /2014). All clinical study participants provided written informed consent before the study.

\section{Consent for publication \\ Not applicable.}

\section{Competing interests}

Authors RM and SJ, who conducted the biochemical analysis, are employed by a non-profit educational institution and have no conflict of interest. Akay Flavours \& Aromatics, the makers of the PCE nutraceutical ingredient, employs JM and KIM. Life Extension, a dietary supplement company that sells finished products containing PCE, employs DKS and AGS. JM and KIM were involved in developing the specifications for and commercialization of PCE, which is not patented. None of the authors own shares in Akay Flavours \& Aromatics or Life Extension or stand to make any personal financial gains from the sale of PCE or products containing PCE. Akay Flavours \& Aromatics and Life Extension are two completely unrelated entities with no financial ties to each other. Life Extension purchases dietary ingredients from Akay Flavours \& Aromatics and did not contribute financially to this research project, but rather collaborated on a scientific level for data analysis and manuscript preparation.

\section{Publisher's Note}

Springer Nature remains neutral with regard to jurisdictional claims in published maps and institutional affiliations.

\section{Author details}

${ }^{1}$ Department of Biochemistry, St. Thomas College, Pala, Kerala, India. ${ }^{2}$ R\&D center, Akay Flavours \& Aromatics Pvt Ltd, Cochin, India. ${ }^{3}$ Life Extension, Ft. Lauderdale, FL 33308, USA.

Received: 30 January 2019 Accepted: 16 April 2019

Published online: 07 May 2019

\section{References}

1. Centers for Disease Control and Prevention. National Diabetes Statistics Report. Estimates of diabetes and its burden in the United States, 2014. Atlanta. In: GA: US Department of Health and Human Services; 2014.

2. Pilkington R, Taylor AW, Hugo G, Wittert G. Are baby boomers healthier than generation $X$ ? A profile of Australia's working generations using National Health Survey data. PLoS One. 2014;9(3):e93087.

3. Nishida C, Uauy R, Kumanyika S, Shetty P. The joint WHO/FAO expert consultation on diet, nutrition and the prevention of chronic diseases: process, product and policy implications. Public Health Nutr. 2004;7(1a):245-50.

4. Drewnowski A. Concept of a nutritious food: toward a nutrient density score. Am J Clin Nutr. 2005;82(4):721-32.

5. Miranda AM, Steluti J, Fisberg RM, Marchioni DM. Association between polyphenol intake and hypertension in adults and older adults: a population-based study in Brazil. PLoS One. 2016;11(10):e0165791.

6. Petrick JL, Steck SE, Bradshaw PT, Trivers KF, Abrahamson PE, Engel LS, et al. Dietary intake of flavonoids and oesophageal and gastric cancer: incidence and survival in the United States of America (USA). Br J Cancer. 2015;112(7):1291-300.

7. Tresserra-Rimbau A, Guasch-Ferre M, Salas-Salvado J, Toledo E, Corella D, Castaner $\mathrm{O}$, et al. Intake of Total polyphenols and some classes of polyphenols is inversely associated with diabetes in elderly people at high cardiovascular disease risk. J Nutr. 2016. 
8. Wedick NM, Pan A, Cassidy A, Rimm EB, Sampson L, Rosner B, et al. Dietary flavonoid intakes and risk of type 2 diabetes in US men and women. Am J Clin Nutr. 2012;95(4):925-33.

9. Yeon JY, Bae YJ, Kim EY, Lee EJ. Association between flavonoid intake and diabetes risk among the Koreans. Clin Chim Acta. 2015;439:225-30.

10. Zamora-Ros R, Forouhi NG, Sharp SJ, Gonzalez CA, Buijsse B, Guevara M, et al. The association between dietary flavonoid and lignan intakes and incident type 2 diabetes in European populations: the EPIC-InterAct study. Diabetes Care. 2013;36(12):3961-70.

11. Issac A, Gopakumar G, Kuttan R, Maliakel B, Krishnakumar IM. Safety and anti-ulcerogenic activity of a novel polyphenol-rich extract of clove buds (Syzygium aromaticum L). Food and Function. 2015;6(3):842-52.

12. Johannah NM, Renny RM, Gopakumar G, Maliakel B, Sureshkumar D, Krishnakumar IM. Beyond the flavour: a de-flavoured polyphenol rich extract of clove buds (Syzygium aromaticum L) as a novel dietary antioxidant ingredient. Food and Function. 2015;6(10):3373-82.

13. Jose SP, Ratheesh M, Asha S, Krishnakumar I, Sandya S, Girish KB. Hepatoprotective effect of clove bud polyphenols (Syzygium aromaticum L.) $\left(\right.$ Clovinol $\left.^{\circledR}\right)$ by modulating alcohol induced oxidative stress and inflammation. J Food Res. 2017;7(1).

14. Sharabi K, Tavares CDJ, Rines AK, Puigserver P. Molecular pathophysiology of hepatic glucose production. Mol Asp Med. 2015;46:21-33.

15. Kleemann $R$, Van Erk M, Verschuren L, Van Den Hoek AM, Koek M, Wielinga PY, et al. Time-resolved and tissue-specific systems analysis of the pathogenesis of insulin resistance. PLoS One. 2010;5(1).

16. Jose SP, Ratheesh M, Asha S, Krishnakumar IM, Sandya S. Girish KB. Hepatoprotective effect of clove bud polyphenols (Syzygium aromaticum L.) $\left(\right.$ Clovino $\left.^{\oplus}\right)$ by modulating alcohol induced oxidative stress and inflammation. Journal of food research; Vol 7. In: No 1 (2018) DO - 105539/jfrv7n1p10; 2017.

17. Yap A, Nishiumi S, Yoshida K-i, Ashida H. Rat L6 myotubes as an in vitro model system to study GLUT4-dependent glucose uptake stimulated by inositol derivatives. Cytotechnology. 2007:55(2-3):103-8.

18. Caton PW, Nayuni NK, Kieswich J, Khan NQ, Yaqoob MM, Corder R. Metformin suppresses hepatic gluconeogenesis through induction of SIRT1 and GCN5. J Endocrinol. 2010;205(1):97-106.

19. Matsui T, Ueda T, Oki T, Sugita K, Terahara N, Matsumoto K. Alphaglucosidase inhibitory action of natural acylated anthocyanins. 2. Alphaglucosidase inhibition by isolated acylated anthocyanins. J Agric Food Chem. 2001;49(4):1952-6.

20. Bernfeld P. [17] Amylases, $a$ and $\beta$. Methods in Enzymology. 1: Academic Press; 1955. p. 149-58

21. Sanae F, Kamiyama O, Ikeda-Obatake K, Higashi Y, Asano N, Adachi I, et al. Effects of eugenol-reduced clove extract on glycogen phosphorylase $b$ and the development of diabetes in db/db mice. Food Funct. 2014;5(2):214-9.

22. Nathan DM, Davidson MB, DeFronzo RA, Heine RJ, Henry RR, Pratley R, et al. Impaired fasting glucose and impaired glucose tolerance: implications for care. Diabetes Care. 2007:30(3):753-9.

23. American Diabetes Association. Postprandial blood glucose. Diabetes Care. 2001:24(4):775-8.

24. Shrom D, Sarwat S, llag L, Bloomgarden ZT. Does A1c consistently reflect mean plasma glucose? J Diabetes. 2010;2(2):92-6.

25. Hanefeld M, Fischer S, Julius U, Schulze J, Schwanebeck U, Schmechel H, et al. Risk factors for myocardial infarction and death in newly detected NIDDM: the diabetes intervention study, 11-year follow-up. Diabetologia. 1996;39(12):1577-83.

26. Meigs JB, Nathan DM, D'Agostino RB Sr, Wilson PWF. Fasting and postchallenge glycemia and cardiovascular disease risk: the Framingham offspring study. Diabetes Care. 2002;25(10):1845-50.

27. Barclay AW, Petocz P, McMillan-Price J, Flood VM, Prvan T, Mitchell P, et al. Glycemic index, glycemic load, and chronic disease risk - a metaanalysis of observational studies. Am J Clin Nutr. 2008;87(3):627-37.

28. Ceriello A. Postprandial hyperglycemia and diabetes complications: is it time to treat? Diabetes. 2005;54(1):1-7.

29. Bonora E, Muggeo M. Postprandial blood glucose as a risk factor for cardiovascular disease in type II diabetes: the epidemiological evidence. Diabetologia. 2001;44(12):2107-14.

30. Cavalot F, Petrelli A, Traversa M, Bonomo K, Fiora E, Conti M, et al. Postprandial blood glucose is a stronger predictor of cardiovascular events than fasting blood glucose in type 2 diabetes mellitus, particularly in women: lessons from the san Luigi Gonzaga diabetes study. J Clin Endocrinol Metab. 2006;91(3):813-9.
31. Lefèbvre PJ, Scheen AJ. The postprandial state and risk of cardiovascular disease. Diabetic Med. 1998;15(SUPPL. 4:S63-S8.

32. Hanefeld M, Koehler C, Schaper F, Fuecker K, Henkel E, TemelkovaKurktschiev T. Postprandial plasma glucose is an independent risk factor for increased carotid intima-media thickness in non-diabetic individuals. Atherosclerosis. 1999;144(1):229-35.

33. Abbatecola AM, Rizzo MR, Barbieri M, Grella R, Arciello A, Laieta MT, et al. Postprandial plasma glucose excursions and cognitive functioning in aged type 2 diabetics. Neurology. 2006;67(2):235-40.

34. Chiasson JL, Josse RG, Gomis R, Hanefeld M, Karasik A, Laakso M. Acarbose treatment and the risk of cardiovascular disease and hypertension in patients with impaired glucose tolerance: the STOP-NIDDM trial. J Am Med Assoc. 2003;290(4):486-94.

35. Kirpichnikov D, McFarlane SI, Sowers JR. Metformin: An update. Ann Intern Med. 2002;137(1):25-33.

\section{Ready to submit your research? Choose BMC and benefit from:}

- fast, convenient online submission

- thorough peer review by experienced researchers in your field

- rapid publication on acceptance

- support for research data, including large and complex data types

- gold Open Access which fosters wider collaboration and increased citations

- maximum visibility for your research: over $100 \mathrm{M}$ website views per year

At $\mathrm{BMC}$, research is always in progress.

Learn more biomedcentral.com/submissions 